\title{
Antimicrobial activity of grape seed extract on Alicyclobacillus acidoterrestris DSM 3922 vegetative cells and spores in apple juice
}

\author{
Celenk Molva, Ayse Handan Baysal \\ Department of Food Engineering, Izmir Institute of Technology, Urla, 35437, Izmir, Turkey
}

\section{A R T I C L E I N F O}

\section{Article history:}

Received 2 April 2014

Received in revised form

20 July 2014

Accepted 22 July 2014

Available online 31 July 2014

\section{Keywords:}

Alicyclobacillus acidoterrestris

Juice spoilage

Natural extracts

Sporulation media

Modeling

Chemical compounds studied in this article:

Grape seed extract (proanthocyanidins)

(PubChem CID: 108065)

gallic acid (PubChem CID: 370)

disodium carbonate (PubChem CID: 10340)

sodium acetate trihydrate (PubChem CID:

23665405)

2,4,6-tripyridyl-s-triazine (PubChem CID:

77258)

iron chloride (PubChem CID: 24380)

\begin{abstract}
A B S T R A C T
The present study evaluated the antimicrobial activity of grape seed extract (GSE) against Alicyclobacillus acidoterrestris vegetative cells and spores in apple juice $\left(\mathrm{pH} 3.82,{ }^{\circ}\right.$ Brix 11.3$)$ during storage at $37{ }^{\circ} \mathrm{C}$. After $336 \mathrm{~h}$, reductions in the cell numbers were 3.14, 3.55, 3.8, 4.1, and $4.63 \log \mathrm{CFU} / \mathrm{mL}$ in the apple juice with $0.23,0.45,0.9,1.8$, and $3.6 \%$ of GSE, respectively. The Weibull was found to be the best fitted model for cell inactivation kinetics $\left(R^{2}>0.988\right)$. Moreover, the spores produced on different sporulation media (potato dextrose agar, malt extract agar, Bacillus acidoterrestris agar, and Bacillus acidocaldarius agar) were treated with GSE $(0-1.9 \%, \mathrm{v} / \mathrm{v})$. While control spores in apple juice without GSE increased by $2.2-2.6 \log \mathrm{CFU} / \mathrm{mL}$ within the first $48 \mathrm{~h}, 0.9 \%$ and $1.8 \%$ of GSE inhibited the growth from all spore suspensions. Finally, scanning electron microscopy (SEM) indicated that the main target of the GSE may be the membrane of A. acidoterrestris cells leading to leakage of cellular constituents and may prevent the development of spores into vegetative cells. This study highlights the potential use of the by-products of the fruit juice/ beverage industry as natural antimicrobials to inhibit the growth of $A$. acidoterrestris.
\end{abstract}

() 2014 Elsevier Ltd. All rights reserved.

\section{Introduction}

Alicyclobacillus spp. are Gram-positive, non-pathogenic, obligate aerobic, rod-shaped, thermophilic and acidophilic spore-forming bacteria (Chang \& Kang, 2004). Growth of alicyclobacilli has been detected in a wide range of fruit juices such as apple, tomato, white grape, grapefruit, orange and pineapple juices. However, it is not detected in red grape juices and Cupuacu (Silva \& Gibbs, 2001). Alicyclobacillus acidoterrestris which is considered as the most prominent species within alicyclobacilli has the ability to produce taint compounds such as guaiacol and halophenols in fruit juices (Bevilacqua, Campaniello, Speranza, Sinigaglia, \& Corbo, 2013). The detectable concentration of guaiacol in fruit juices reported as $2 \mathrm{ppb}$ can be produced by about $10^{4}-10^{5} \mathrm{CFU} / \mathrm{mL}$ of

\footnotetext{
* Corresponding author. Tel.: +90 232 7506187; fax: +90 2327506196 .

E-mail address: handanbaysal@iyte.edu.tr (A.H. Baysal).
}

A. acidoterrestris cells (Bahçeci, Gökmen, \& Acar, 2005; Gocmen, Elston, Williams, Parish, \& Rouseff, 2005; Pettipher, Osmundson, \& Murphy, 1997).

Nowadays, nonthermal methods such as the usage of natural antimicrobials, high hydrostatic pressure, homogenization pressure, microwave, and ultrasound are being tested to control the growth of alicyclobacilli in foods as an alternative to thermal treatments (Bevilacqua, Sinigaglia, \& Corbo, 2008; Walker \& Phillips, 2008). The use of natural plant extracts as an alternative to chemical or synthetic antimicrobials and antioxidants is an increasing trend in the food industry (Perumalla \& Hettiarachchy, 2011). Leaf extracts from eucalyptus (Takahashi, Kokubo, \& Sakaino, 2004), citrus extract (Bevilacqua et al., 2013) and saponin extract (Alberice, Funes-Huacca, Guterres, \& Carrilho, 2012) are natural extracts that have been tested against A. acidoterrestris alone or in combination with thermal methods. Grape (Vitis vinifera L.) seeds are waste products of the winery and grape juice industry. It is estimated that approximately $13 \%$ of the 
total weight of grapes used for wine making results in grape pomace (Torres et al., 2002). Grape pomace can be used for the isolation of seeds and extraction of polyphenols. Total extractable phenolics in grape are found in about a maximum of $10 \%$ in pulp, $60-70 \%$ in the seeds and $28-35 \%$ in the skin (Shi, Yu, Pohorly, \& Kakuda, 2003). Grape seed extract (GSE) is a by-product derived from the seeds that is extracted, dried and purified to produce a polyphenolic compound rich extract (Lau \& King, 2003). This extract has Generally Recognized as Safe (GRAS) status approved by the Food and Drug Administration. It has been proved to possess antimicrobial activity that is attributed to the general mode of action of the phenolics (Perumalla \& Hettiarachchy, 2011). GSE has also been reported to have many pharmacological and biochemical actions such as anti-inflammatory, cardioprotective, chemopreventive, anticarcinogenic, and antioxidant activities (Mahmoud, 2013).

To the best of our knowledge, no data on the antimicrobial activity of GSE in a real food system, such as apple juice, on the cells and spores of $A$. acidoterrestris have been reported in literature. In the current study, the main objectives were to evaluate the use of GSE as a natural compound to control cells and spores in apple juice; to mathematically model the cell inactivation behavior, to determine the effect of sporulation media on the antimicrobial resistance of spores and finally to examine the ultrastructural changes by scanning electron microscopy studies.

\section{Material and methods}

\subsection{Microorganism and spore production}

A. acidoterrestris DSM 3922 was kindly provided by Karl Poralla (Deutsche Sammlung von Mikroorganismem und Zellkulturen's collection, Braunschweig, Germany) and was used as the test microorganism in this study. Cells of $A$. acidoterrestris were pre-cultured at $43{ }^{\circ} \mathrm{C}$ for $4 \mathrm{~h}$ in $10 \mathrm{~mL}$ Bacillus acidoterrestris broth (BAT, Döhler, Germany) to achieve a cell density of approximately $10^{6}-10^{7} \mathrm{CFU} / \mathrm{mL}$. Then, $100 \mu \mathrm{L}$ culture was spread onto Bacillus acidoterrestris agar (BATA, Merck), Bacillus acidocaldarius agar (BAA), (Darland \& Brock, 1971), potato dextrose agar (PDA, BD Difco), malt extract agar (MEA, Oxoid). All inoculated plates were incubated at $43^{\circ} \mathrm{C}$. Sporulation was determined by direct observation of free, fully refractile spores under the phase-contrast microscope (Olympus CX31, Japan). After reaching more than $85-90 \%$ of sporulation, spores were harvested by depositing 1-2 $\mathrm{mL}$ of cold sterile deionized water onto the surface of plates and dislodged from the agar surface by gently rubbing with a sterile swab. Spore suspensions were centrifuged at $4000 \mathrm{rpm}$ for $20 \mathrm{~min}\left(4^{\circ} \mathrm{C}\right)$. The supernatant was discarded and the pellet was resuspended in sterile deionized water. Suspension was centrifuged again at $4000 \mathrm{rpm}$ for $10 \mathrm{~min}\left(4^{\circ} \mathrm{C}\right)$. This step was repeated three times. The final pellet was resuspended in sterile deionized water and mixed thoroughly. The spore suspensions were stored in $1.8 \mathrm{~mL}$ eppendorf tubes at $-20{ }^{\circ} \mathrm{C}$ for further use (Murray, Gurtler, Ryu, Harrison, \& Beuchat, 2007).

\subsection{Apple juice}

Concentrated apple juice ( $70.3^{\circ}$ Brix) was provided by ASYA Fruit Juice and Food Ind. Inc. (Isparta, Turkey) and reconstituted to $11.3 \pm 0.1{ }^{\circ}$ Brix by a refractometer (Mettler Toledo, USA). Measurements were performed at $20^{\circ} \mathrm{C}$. The $\mathrm{pH}$ of the reconstituted juice was measured as $3.82 \pm 0.01$ (Hanna instruments, Hungary).

\subsection{Total phenol and ferric reducing antioxidant capacity of grape seed extract}

Commercial liquid extract derived from the grape seed was purchased from a local health food store. The total phenol content of the extract was determined using the Folin-Coicalteu (FC) method (Al-Zoreky, 2009). Briefly, $0.2 \mathrm{~mL}$ of diluted extract (1/10 and $1 / 20, v / v$ ) was mixed with $1 \mathrm{~mL}$ of 10 -fold diluted $\mathrm{FC}$ reagent and then vortexed. After $3 \mathrm{~min}$ incubation at room temperature, $0.8 \mathrm{~mL}$ of $\mathrm{Na}_{2} \mathrm{CO}_{3}(7.5 \%, \mathrm{w} / \mathrm{v})$ was added, vortexed again and left in the dark. After $1 \mathrm{~h}$, the absorbance of the samples was measured at $765 \mathrm{~nm}$ using a UV/Vis spectrophotometer (Cary 100 Bio, Varian Inc., CA, USA). A calibration curve was prepared with gallic acid $(0-0.09 \mathrm{mg} / \mathrm{mL})$. The results were expressed in gallic acid equivalents (GAE) in $\mathrm{mg} / \mathrm{mL}$ extract. To measure the antioxidant ability of grape seed extract to reduce ferric iron, ferric reducing antioxidant power (FRAP) assay was used. Firstly, stock solutions of $300 \mathrm{mM}$ sodium acetate buffer ( $\mathrm{pH}$ 3.6), $10 \mathrm{mM} \mathrm{2,} \mathrm{4,} \mathrm{6-tripyridyl-s-triazine}$ (TPTZ dissolved in $40 \mathrm{mM} \mathrm{HCl}), 20 \mathrm{mM}$ ferric chloride $\left(\mathrm{FeCl}_{3} .6 \mathrm{H}_{2} \mathrm{O}\right.$ ) were prepared. The FRAP reagent was freshly prepared by mixing the stock solutions in 10:1:1 ratio, shaken by vortexing and kept in the dark for $10 \mathrm{~min}$ at $37^{\circ} \mathrm{C}$. Then, $0.1 \mathrm{~mL}$ diluted grape seed extract $(1 / 1000,1 / 2000)$ was mixed with $4 \mathrm{~mL}$ FRAP reagent. After $10 \mathrm{~min}$, the absorbance was determined at $593 \mathrm{~nm}$. The FRAP solution was used as a blank. The results were expressed as Trolox equivalents (TE) using a calibration curve in the range of $0-0.1 \mathrm{mM}$. All assays were done in triplicate (Bi et al., 2013).

\subsection{Antimicrobial assay}

Antimicrobial activity was tested against both $A$. acidoterrestris cells and spores in apple juice containing different concentrations of GSE. First, bacterial cells were grown overnight on PDA at $43^{\circ} \mathrm{C}$. The colonies were suspended in $10 \mathrm{~mL}$ Maximum Recovery Diluent (MRD, Oxoid) to obtain a bacterial density of McFarland 2.0 $\left(10^{7} \mathrm{CFU} / \mathrm{mL}\right.$ ) by using a Densitometer (Den-1, HVD Life Sciences, Austria). Also, the spore stocks $\left(10^{7} \mathrm{CFU} / \mathrm{mL}\right)$ were thawed, heatactivated at $80{ }^{\circ} \mathrm{C}$ for $10 \mathrm{~min}$ and then cooled on ice. After centrifugation of the cell or spore suspension $(1 \mathrm{~mL})$, the pellet was dissolved in $10 \mathrm{~mL}$ apple juice. Sterile test tubes containing $9 \mathrm{~mL}$ apple juice with GSE were inoculated separately with $1 \mathrm{~mL}$ of the bacterial or spore suspension. The final concentrations of the GSE in the apple juice were $0 \%, 0.06 \%, 0.12 \%, 0.23 \%, 0.45 \%, 0.9 \%, 1.8 \%, 3.6 \%$ $(\mathrm{v} / \mathrm{v})$. The initial population was determined for each concentration after inoculation. Next, the samples were incubated and shaken at $37^{\circ} \mathrm{C}$ for $120 \mathrm{rpm}$ in an incubator. At $24 \mathrm{~h}$ time intervals, up to $336 \mathrm{~h}$ the viable counts were determined by spread plating onto the surface of PDA ( $\mathrm{pH} 3.5$ ) and incubating the plates at $43^{\circ} \mathrm{C}$ for $48 \mathrm{~h}$.

\subsection{Modeling of inactivation data}

The viable cell counts were transformed to $\log _{10}$ values and survival curves were obtained by plotting the logarithm of survivors against the treatment time (h). Inactivation data were analyzed by the GlnaFiT tool (Geeraerd, Valdramidis, \& Van Impe, 2005) using Log-linear tail (Geeraerd, Herremans, \& Van Impe, 2000) and the Weibull models (Mafart, Couvert, Gaillard, \& Leguerinel, 2002).

The Weibull model was used with the Eq. (1) (Mafart et al., 2002);

$\log N_{t}=\log N_{0}(t / \delta)^{\beta}$

where $N_{t}$ represents the number of surviving population after time $t(\mathrm{~h}) ; N_{0}$ is the initial number of microorganisms $(t=0) ; \beta$ is the 
shape parameter (dimensionless) showing upward $(\beta<1)$ and downward concavity $(\beta>1)$. Upward concave curves are associated with the adaptation of the remaining cells to the applied stress. Downward concave indicates the increased damage of the remaining cells in applied stress (van Boekel, 2002). Also, $\delta$ is the scale parameter $(\mathrm{h})$ and corresponds to the time for the first decimal reduction (De Oliveira, Soares, \& Piccoli, 2013). Time to 4-log reduction $\left(t_{4 \mathrm{D}}\right)$ was calculated by Eq. (2) (Levy, Aubert, Lacour, \& Carlin, 2012).

$t_{4 \mathrm{D}}=\delta \cdot(4)^{1 / \beta}$

The Log-linear tail model was used with the Eq. (3) (Geeraerd et al., 2000);

$\log N_{t}=\log \left(\left(10^{\log N_{\mathrm{o}}}-10^{\log N_{\mathrm{res}}}\right)\right) \cdot e^{\left(-k_{\max } t\right)}+10^{\log N_{\mathrm{res}}}$

where $N_{\text {res }}$ is the residual population density $(\log \mathrm{CFU} / \mathrm{mL})$ that characterizes tailing of inactivation kinetics (Hereu, Dalgaard, Garriga, Aymerich, \& Bover-Cid, 2012) and $k_{\max }$ is the inactivation rate of the log-linear part of the curve $\left(\mathrm{h}^{-1}\right)$ (Izquier \& GómezLópez, 2011).

The values of root mean square error (RMSE), coefficient of determination $\left(R^{2}\right)$ and adjusted $R^{2}\left(\operatorname{adj}-R^{2}\right)$ values were compared for model evaluation. The best fit of the data is obtained when RMSE is the smallest and $R^{2}$ value is close to 1 . If two models have the same or similar RMSE, the simpler one can be chosen (Berney, Weilenmann, Simonetti, \& Egli, 2006).

\subsection{Scanning electron microscopy}

Ultrastructural changes in A. acidoterrestris bacterial cells and spores treated by GSE were determined by SEM imaging. Firstly, untreated and treated samples were centrifuged $(14,000 \mathrm{rpm}$ for $10 \mathrm{~min})$. Next, the resultant pellets were suspended in sterile deionized water and the suspension was centrifuged again. This washing step was repeated three times. After that, the pellets were resuspended in sterile deionized water. Finally, the suspension $(10 \mu \mathrm{L})$ was fixed onto clean glass slides and air-dried overnight for SEM. For SEM imaging, samples were coated with gold at a vacuum of $0.09 \mathrm{mbar}$, for $90 \mathrm{~s}$, at $15 \mathrm{kV}$, in argon gas at a power of $15 \mathrm{~mA}$ and examined with a scanning electron microscope (Phillips XL-30S FEG).

\subsection{Statistical analysis}

The data were obtained from independent experiments with three repetitions, and the viable counts were performed in duplicates. Means and standard deviations were calculated by Microsoft Excel 2003 (Microsoft corp., USA). The Tukey-Kramer test was used to compare the means of treated groups $(p<0.05)$ (Minitab 16).

\section{Results and discussion}

\subsection{Total phenolics in grape seed extract and ferric reducing antioxidant capacity}

Phenolic compounds are important for their antimicrobial activity. Therefore, total phenolic content of the liquid extract was determined. The total phenol content of GSE was found as $21.24 \pm 0.36 \mathrm{mg} \mathrm{GAE} / \mathrm{mL}$ extract. The total phenol content of the GSE obtained from juice and wine was reported to be $6.04 \pm 0.69$ and $2.41 \pm 0.34 \mathrm{mg} \mathrm{GAE} / \mathrm{mL}$, respectively (Bijak et al., 2011; Delgado Adámez, Gamero Samino, Valdés Sánchez, \& González-Gómez, 2012). The differences among the levels of phenolic compounds in the seeds from different varieties arise from many factors including climate, ripeness degree, berry size and grapevine variety (Rockenbach et al., 2011). In fact, GSE is shown as a rich source of polyphenols such as phenolic acids, flavonoids (anthocyanidins, flavanols such as catechin and proanthocyanidins, flavanones, flavones, flavonols and isoflavones), stilbenes and lignans (Manach, Scalbert, Morand, Remesy, \& Jimenez, 2004).

Grape seeds exhibit the highest antioxidant activity followed by the skin and the flesh (Perumalla \& Hettiarachchy, 2011). It was found that the tested GSE also had high power reduction of $110.90 \mathrm{mM}$ Trolox equivalent. The antioxidant potential of GSE is primarily due to the flavonoids that can perform scavenging activity on free radicals (superoxide, hydroxyl and 2,2-diphenly-2picrylhydrazyl), metal chelating properties, reduction of hydroperoxide formation and their effects on cell signaling pathways and gene expression. The presence of the functional $-\mathrm{OH}$ group in the structure and its position on the ring of the flavanoid molecule determine its antioxidant potential (Perumalla \& Hettiarachchy, 2011).

\subsection{Antimicrobial activity on vegetative cells and modeling inactivation data}

The antimicrobial effect of GSE in apple juice is shown in Table 1. The concentration of GSE in the apple juice ranged from 0 to $3.6 \%(\mathrm{v} / \mathrm{v})$. The antimicrobial activity of the GSE at all tested concentrations caused significant reduction in cell counts but did not completely eliminate the microbial population under the tested conditions (Table 1 ). The control cells which were grown in apple juice without GSE $(0 \%, v / v)$ attained approximately $7.0 \log \mathrm{CFU} / \mathrm{mL}$ after $24-\mathrm{h}$ of incubation in apple juice. There were no significant differences $(p>0.05)$ in the counts of A. acidoterrestris cells in the apple juice with all tested concentrations after $24 \mathrm{~h}$. Also, the cell counts were statistically similar in

Table 1

Counts of $A$. acidoterrestris vegetative cells $\left(\log \mathrm{CFU} / \mathrm{mL}\right.$ ) in apple juice containing different concentrations of grape seed extract at $37{ }^{\circ} \mathrm{C}$ during storage*

\begin{tabular}{|c|c|c|c|c|c|c|}
\hline Storage (h) & $0.23 \%$ & $0.45 \%$ & $0.9 \%$ & $1.8 \%$ & $3.6 \%$ & Control \\
\hline 0 & $5.45(0.12)^{\text {Acd }}$ & $5.47(0.06)^{\mathrm{Ac}}$ & $5.69(0.05)^{\mathrm{Ab}}$ & $6.01(0.03)^{\mathrm{Aa}}$ & $6.01(0.01)^{\mathrm{Aa}}$ & $5.27(0.05)^{\mathrm{Dd}}$ \\
\hline 24 & $4.27(0.13)^{\mathrm{Bb}}$ & $4.16(0.04)^{\mathrm{Bb}}$ & $4.07(0.12)^{\mathrm{Bb}}$ & $4.00(0.07)^{\mathrm{Bb}}$ & $4.01(0.08)^{\mathrm{Bb}}$ & $7.09(0.33)^{\mathrm{ABa}}$ \\
\hline 48 & $4.19(0.06)^{\mathrm{Bb}}$ & $3.90(0.04)^{\mathrm{BCbc}}$ & $3.75(0.16)^{\mathrm{Bc}}$ & $3.64(0.12)^{\mathrm{Bc}}$ & $3.79(0.12)^{\mathrm{Bc}}$ & $6.99(0.14)^{\mathrm{ABa}}$ \\
\hline 72 & $3.88(0.06)^{\mathrm{Bb}}$ & $3.48(0.19)^{\mathrm{Cbc}}$ & $3.31(0.01)^{\mathrm{Cc}}$ & $3.19(0.08)^{\mathrm{Cc}}$ & $3.28(0.14)^{\mathrm{BC}}$ & $6.87(0.25)^{\mathrm{ABa}}$ \\
\hline 168 & $3.22(0.23)^{\mathrm{Cb}}$ & $2.43(0.19)^{\mathrm{Dc}}$ & $2.29(0.11)^{\mathrm{Dc}}$ & $2.28(0.16)^{\mathrm{Dc}}$ & $2.32(0.13)^{\mathrm{Cc}}$ & $7.23(0.14)^{\mathrm{Aa}}$ \\
\hline 240 & $2.98(0.11)^{\mathrm{Cb}}$ & $2.33(0.20)^{\mathrm{DEbc}}$ & $2.01(0.20)^{\mathrm{DEC}}$ & $2.11(0.10)^{\mathrm{Dc}}$ & $1.65(0.58)^{\mathrm{CDC}}$ & $6.14(0.13)^{\mathrm{Ca}}$ \\
\hline 336 & $2.31(0.24)^{\mathrm{Db}}$ & $1.92(0.14)^{\mathrm{Ebc}}$ & $1.89(0.14)^{\mathrm{Ebc}}$ & $1.91(0.27)^{\mathrm{Dbc}}$ & $1.38(0.43)^{\mathrm{Dc}}$ & $6.66(0.06)^{\mathrm{BCa}}$ \\
\hline
\end{tabular}

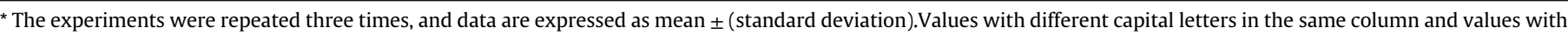
different lower case in the same row are significantly different $(p<0.05)$. 
the apple juice with $0.9 \%, 1.8 \%$, and $3.6 \%$ of GSE during 48,72 and $240 \mathrm{~h}$ of storage. The cell counts treated with $0.45 \%, 0.9 \%, 1.8 \%$, and $3.6 \%$ were statistically the same following $168 \mathrm{~h}$ of treatment. On the other hand, there were only significant differences $(p<0.05)$ among the cells in the apple juice with GSE between $3.6 \%$ and $0.23 \%$ after $336 \mathrm{~h}$. The highest reduction was observed in apple juice with $3.6 \%$ concentration of GSE (4.63 $\log \mathrm{CFU} / \mathrm{mL}$ ) at the end of the treatment. Also, $0.23,0.45,0.9 \%$ and $1.8 \%$ GSE reduced the $\log$ number of cells approximately $3.14,3.55,3.8$, and 4.1, respectively after $336 \mathrm{~h}$ (Table 1 ).

The potential use of GSE as an antimicrobial has been reported previously (Delgado Adámez et al., 2012; Jayaprakasha, Selvi, \& Sakariah, 2003; Rhodes, Mitchell, Wilson, \& Melton,
2006; Silván et al., 2013; Sivarooban, Hettiarachchy, \& Johnson, 2008). However, so far, no data have been published on the antimicrobial activities of the GSE against $A$. acidoterrestris in fruit juices. In the present study, higher inactivation rates were obtained against $A$. acidoterrestris vegetative cells in the apple juice ( $\mathrm{pH}$ 3.82, Brix $^{\circ} 11.3$ ) with GSE. There might be three reasons for higher reductions in cell counts of $A$. acidoterrestris in the apple juice with GSE. In fact, Gram-positive bacteria are more sensitive to natural extracts than Gram-negative due to the absence of lipopolysaccharide layer that reduces the sensitivity (Delgado Adámez et al., 2012). Other possible reasons are the susceptibility of $A$. acidoterrestris to phenolic compounds found in GSE and the susceptibility of bacteria to plant extracts
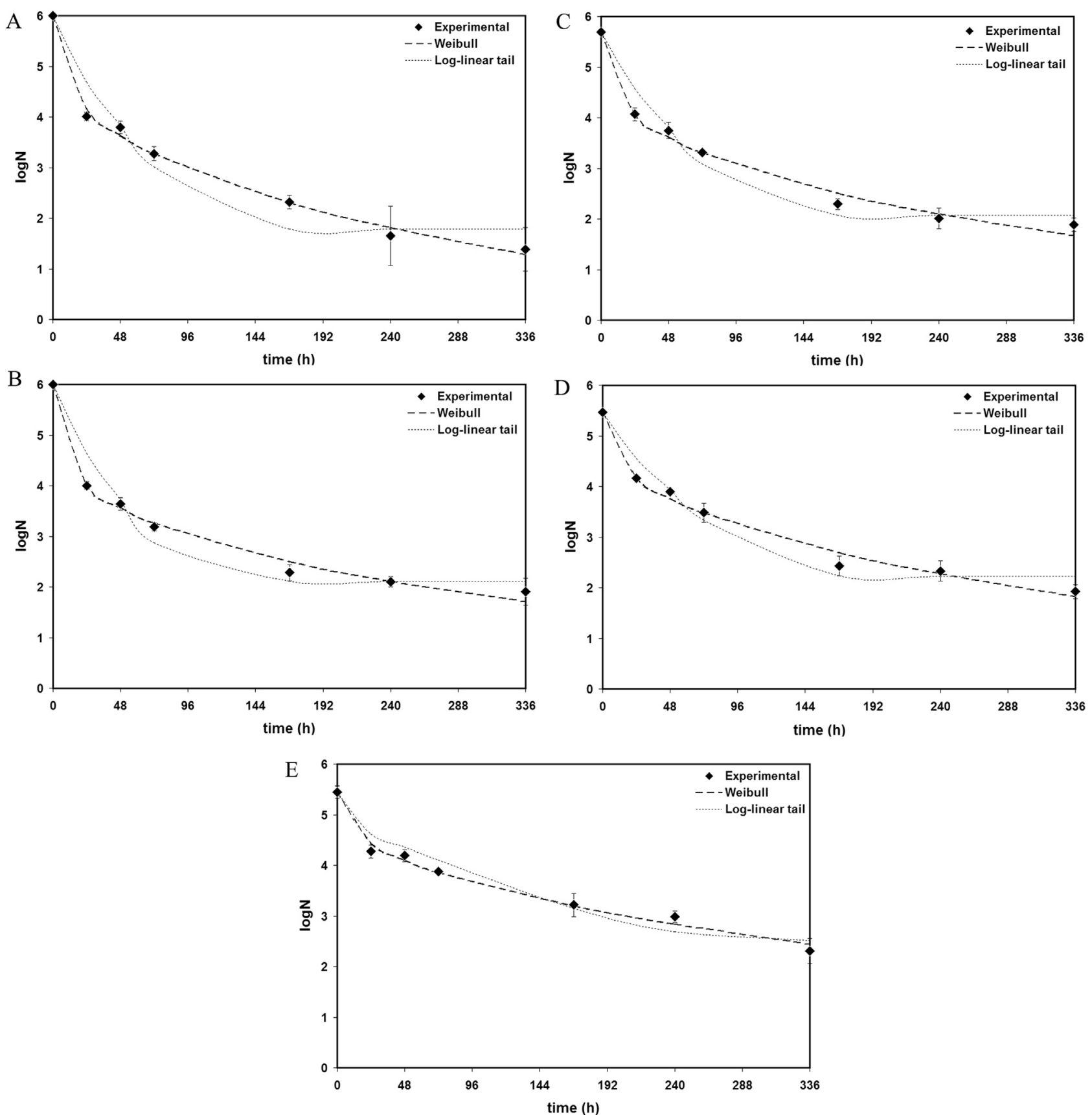

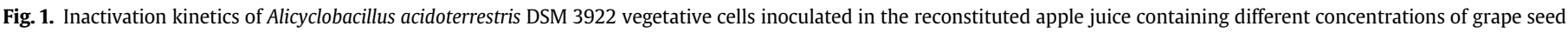
extract. (A) $3.6 \%$, (B) $1.8 \%$, (C) $0.9 \%$, (D) $0.45 \%$, (E) $0.23 \%$. Curves are fitted using Log-linear tail and the Weibull models. 
increases as the $\mathrm{pH}$ of the food decreases (Gutierrez, Barry-Ryan, \& Bourke, 2009).

Natural extracts are less effective in food systems due to the strong interaction between extracts and food components (Kim, Ruengwilysup, \& Fung, 2004). Food components such as proteins, lipids, complex carbohydrates, simple sugars and cations can reduce antimicrobial activity. Carbohydrate-based beverages such as fruit juices and soft drinks are most suitable food matrices to incorporate natural antimicrobials due to their low $\mathrm{pH}$ and also low or absent protein and lipid contents. They provide a homogenous environment for the dispersion of the antimicrobials. There is also a positive relationship between the juice $\mathrm{pH}$ and antimicrobial concentrations used to inhibit and inactivate the target organisms (Davidson, Taylor, Critzer, \& Taylor, 2013).

The antimicrobial assays were carried out in the apple juice rather than model fruit juice or broth system to see the interactions between GSE and fruit juice components. Although most of the literature presents inactivation data from model foods or laboratory media (Negi, 2012), the survival data of A. acidoterrestris cells was obtained in the apple juice containing different concentrations of GSE (Fig. 1). As the data did not follow a first-order kinetics, two mathematical models, Log-linear tail and the Weibull models were used to model the inactivation as a function of time (h). The parameters of both models as well as the statistical indices are shown in Table 2. Visual evaluation of the fitted curves (Fig. 1) and statistical indices (lower RMSE and higher $R^{2}$ values) in Table 2 showed that the Weibull model fitted the experimental data better than Log-linear tail model. The RMSE values of the Weibull model ranged from 0.138 to 0.175 (Table 2). In addition, the Weibull model showed higher $R^{2}(>0.988)$ values. For all treatments, the shape parameter $(\beta)$ was smaller than 0.5 indicating upward concavity. As mentioned earlier, the scale parameter $(\delta)$ represents the first decimal reduction. In general, the time for 4 -log reduction $\left(t_{4 \mathrm{D}}\right)$ of the Weibull model is a better parameter than $\delta$ for evaluation or comparison of the susceptibility of pathogens to environmental stress (Yang, Lee, Afaisen, \& Gadi, 2013). For this reason, $t_{4 D}$ values for the Weibull model were calculated. It was observed that as the concentration increased, $t_{4 \mathrm{D}}$ decreased during storage. As an example, at the concentration of 3.6\% GSE, $\mathrm{t}_{4 \mathrm{D}}$ was found as $204.1 \mathrm{~h}$. At the lowest concentration (0.23\%), it increased to $675.9 \mathrm{~h}$. In previous studies, this model has also been used to estimate bacterial inactivation due to the use of other antimicrobial compounds
(De Oliveira et al., 2013). The $R^{2}$ and RMSE values obtained by fitting Log-linear tail model are also given in Table 2 . The $R^{2}$ values were between 0.897 and 0.958 and RMSE values were between 0.3141 and 0.5495 . The residual population density $\left(\log \mathrm{N}_{\mathrm{res}}\right)$ was 2.49 , $2.22,2.07,2.12$ and $1.79 \mathrm{CFU} / \mathrm{mL}$ for the concentrations of $0.23 \%$, $0.45 \%, 0.9 \%, 1.8 \%$ and $3.6 \%$, respectively. In the present study, the stability of active components in GSE may be lost resulting in lower inactivation rates through to the end of the incubation period. In a similar study (Kao et al., 2010), the inhibitory effect of GSE has been suggested to be affected by the nature of the food and prolonged incubation.

\subsection{Antimicrobial activity on spores}

Control spores in apple juice without GSE increased by 2.2-2.6 $\log \mathrm{CFU} / \mathrm{mL}$ within the first $48 \mathrm{~h}$ of incubation (Fig. 2). The growth was inhibited among spores produced on BATA, BAA and MEA and decreased continuously in the presence of all tested GSE concentrations. After $336 \mathrm{~h}, 1.8 \%$ concentration of GSE resulted in approximately $1.8,1.9,1.4$, and $2.7 \log$ reductions among spores from PDA, BATA, BAA and MEA, respectively. The use of $0.9 \%$ GSE caused 1.8, 1.6, 1.5 and $2.6 \log$ reductions among spores produced on PDA, BATA, BAA and MEA, respectively. In all cases, total population in apple juice containing GSE was less than the control after $48 \mathrm{~h}$. However, the presence of $0.06,0.12,0.23$ and $0.45 \%$ concentration of GSE in the apple juice did not cause a reduction among spores from PDA. After $336 \mathrm{~h}$, the counts of treated spores from PDA at these concentrations attain approximately the numbers of control spores without GSE in the apple juice. Finally, the results indicated that the antimicrobial activity of GSE against A. acidoterrestris spores was variable depending on the concentration and sporulation media used.

\subsection{Scanning electron microscopy}

SEM images demonstrated differences in cell structures when compared with the untreated control bacteria. The control cells are rod-shaped, intact and show smooth surfaces (Fig. 3D). After GSE treatments, the structural integrity of cells was damaged. To determine the effect of higher concentrations on cell surface, $0.9 \%$, $1.8 \%$, and $3.6 \%$ concentrations of GSE were applied for SEM imaging. The cells incubated in the presence of $1.8 \%$ and $3.6 \%$ concentrations

Table 2

Parameters and statistical indices of Log-linear tail and the Weibull models.

\begin{tabular}{|c|c|c|c|c|c|c|c|}
\hline \multirow[t]{2}{*}{ GSE (\%) } & \multicolumn{4}{|c|}{ Weibull } & \multicolumn{3}{|c|}{ Log-linear tail } \\
\hline & $\delta(\mathrm{h})$ & $\beta$ & $t_{4 D}^{\mathrm{a}}(\mathrm{h})$ & Statistical indices & $k_{\max }\left(\mathrm{h}^{-1}\right)$ & $\log \mathrm{N}_{\mathrm{res}}(\mathrm{CFU} / \mathrm{mL})$ & Statistical indices \\
\hline 0.23 & 24.91 & 0.42 & 675.9 & $\begin{array}{l}\operatorname{RMSE}^{\mathrm{b}}=0.138 \\
R^{2 \mathrm{c}}=0.988 \\
R^{2}-\mathrm{adj}^{\mathrm{d}}=0.982\end{array}$ & 0.03 & 2.49 & $\begin{array}{l}\text { RMSE }=0.405 \\
R^{2}=0.897 \\
R^{2} \text {-adj }=0.845\end{array}$ \\
\hline 0.45 & 12.12 & 0.39 & 423.9 & $\begin{array}{l}\text { RMSE }=0.156 \\
R^{2}=0.990 \\
R^{2} \text {-adj }=0.984\end{array}$ & 0.06 & 2.22 & $\begin{array}{l}\text { RMSE }=0.314 \\
R^{2}=0.958 \\
R^{2}-\mathrm{adj}=0.937\end{array}$ \\
\hline 0.9 & 5.63 & 0.34 & 332.1 & $\begin{array}{l}\text { RMSE }=0.175 \\
R^{2}=0.989 \\
R^{2} \text {-adj }=0.984\end{array}$ & 0.07 & 2.07 & $\begin{array}{l}\text { RMSE }=0.361 \\
R^{2}=0.953 \\
R^{2} \text {-adj }=0.930\end{array}$ \\
\hline 1.8 & 2.34 & 0.29 & 278.8 & $\begin{array}{l}\text { RMSE }=0.154 \\
R^{2}=0.992 \\
R^{2} \text {-adj }=0.989\end{array}$ & 0.09 & 2.12 & $\begin{array}{l}\text { RMSE }=0.442 \\
R^{2}=0.937 \\
R^{2} \text {-adj }=0.905\end{array}$ \\
\hline 3.6 & 4.34 & 0.36 & 204.1 & $\begin{array}{l}\text { RMSE }=0.142 \\
R^{2}=0.995 \\
R^{2} \text {-adj }=0.992\end{array}$ & 0.08 & 1.79 & $\begin{array}{l}\text { RMSE }=0.550 \\
R^{2}=0.922 \\
R^{2} \text {-adj }=0.882\end{array}$ \\
\hline
\end{tabular}

\footnotetext{
a Predicted time for 4-log reduction calculated by the Weibull model.

b Root mean square error.

c Coefficient of determination.

d Adjusted regression coefficient.
} 

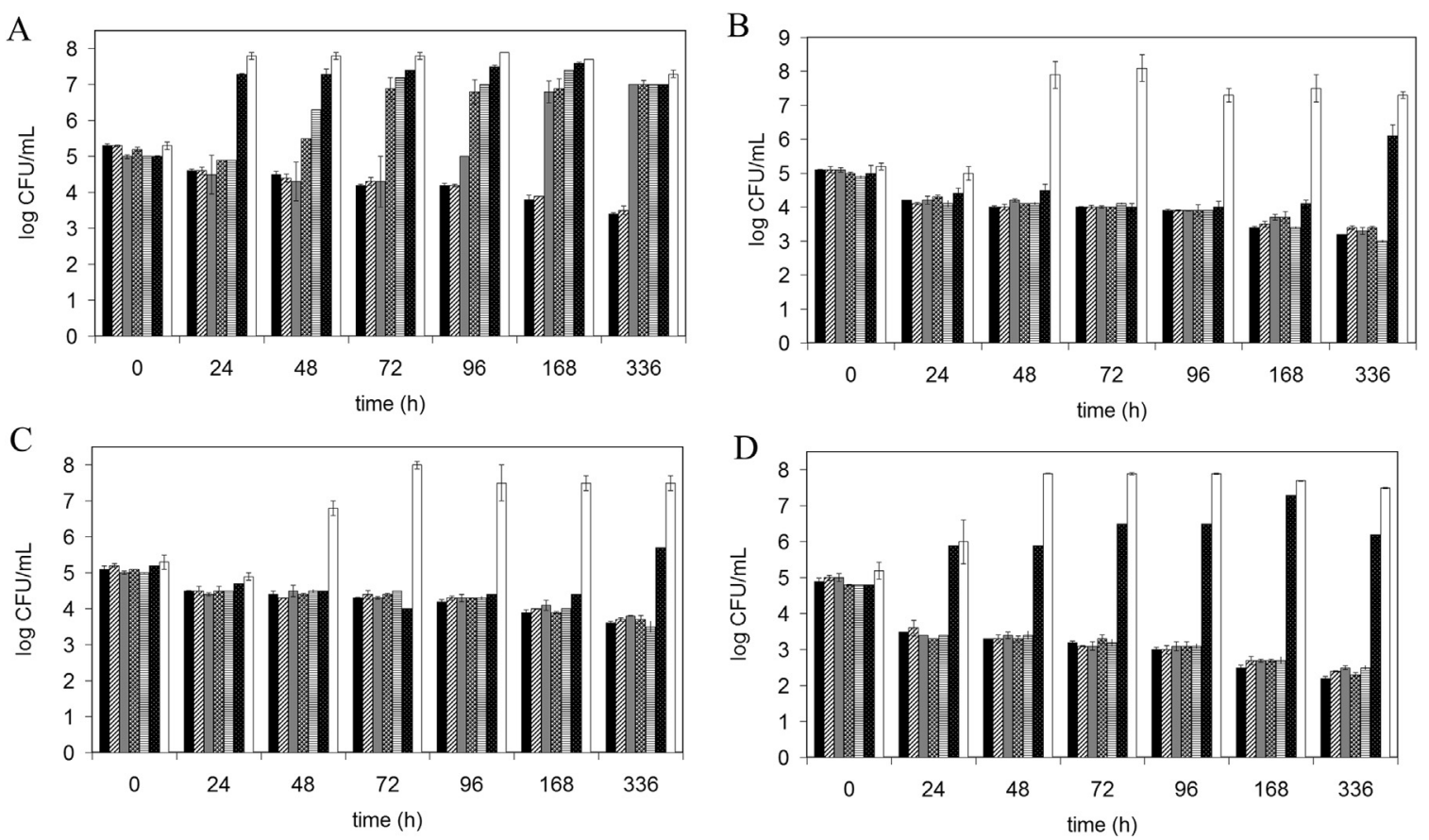

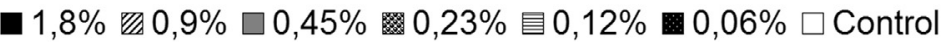

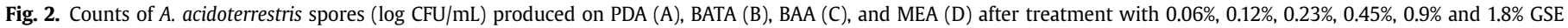
during 14 days. Each spore suspension from different media was inoculated separately in the apple juice and was used as control.

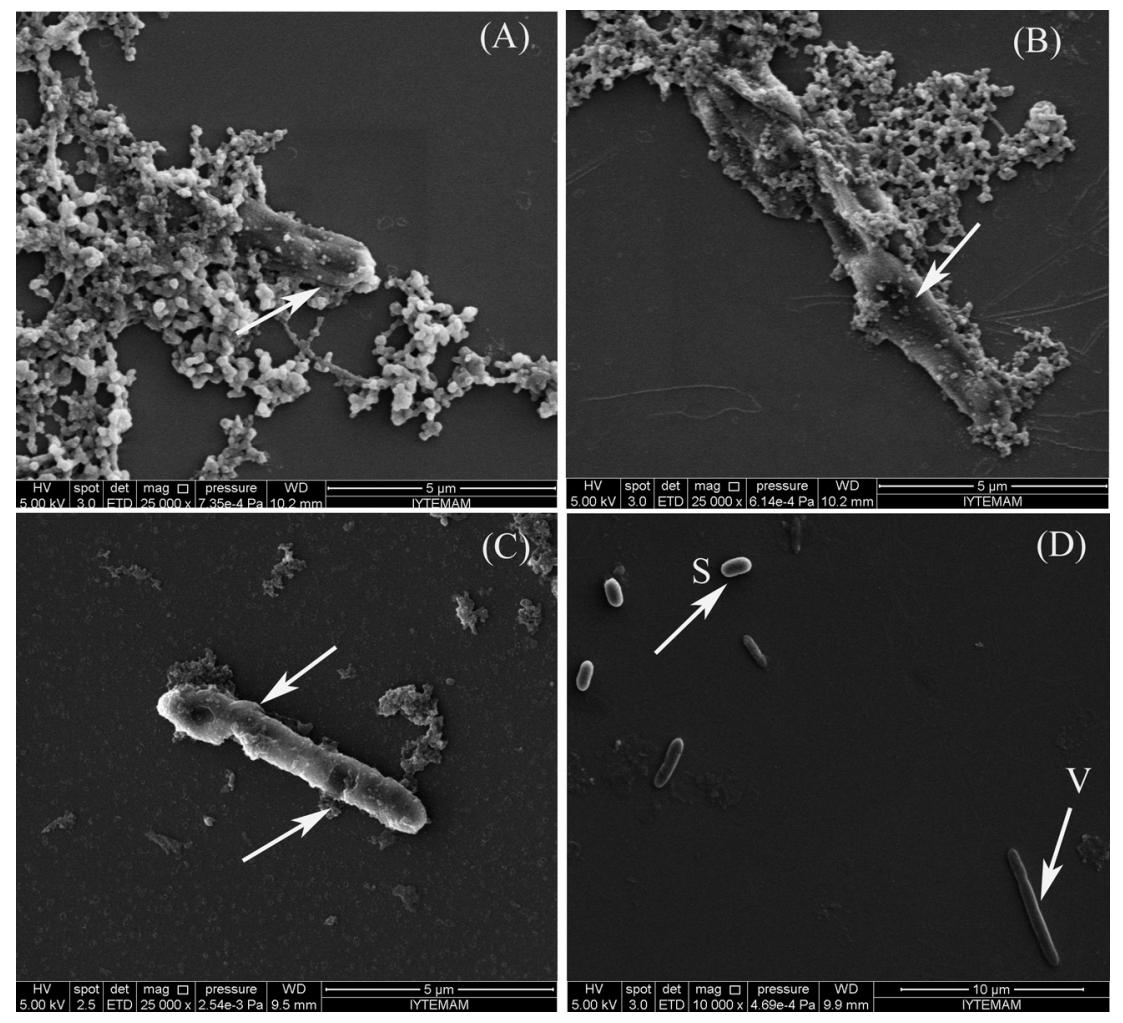

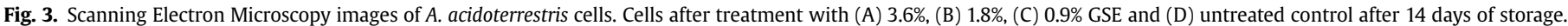

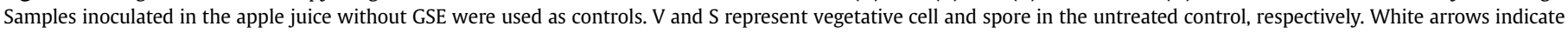
the damage on the cell structure induced by the GSE treatment. 

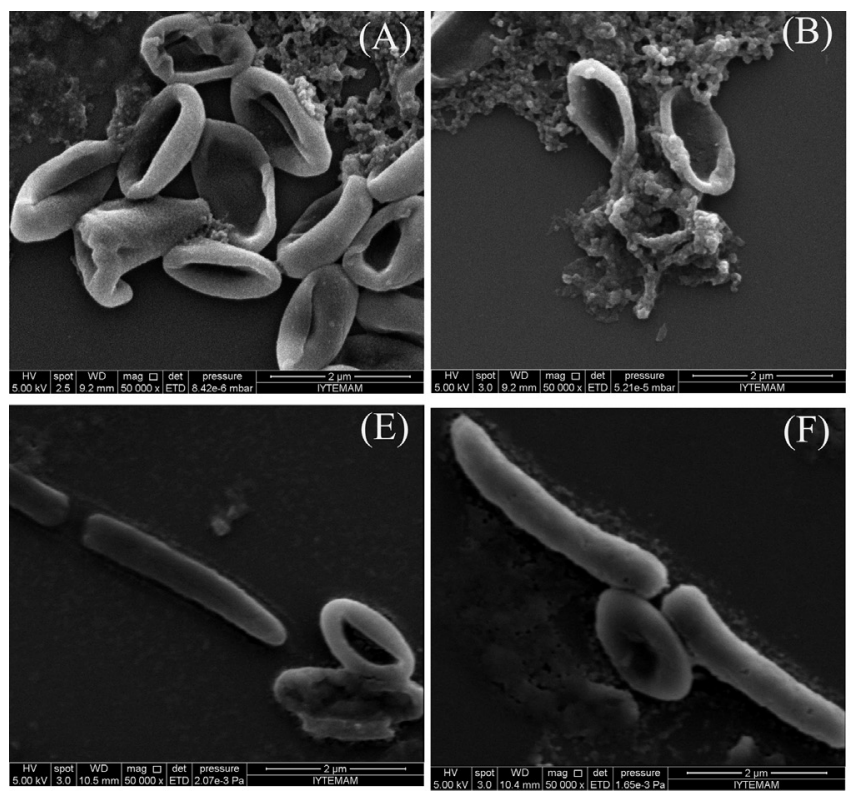
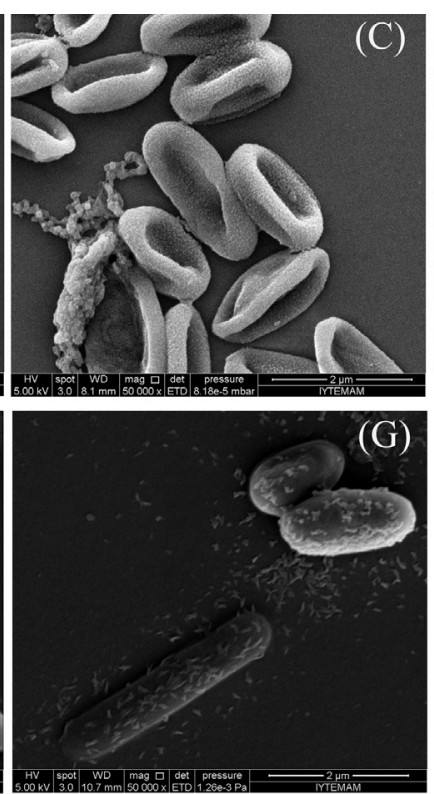
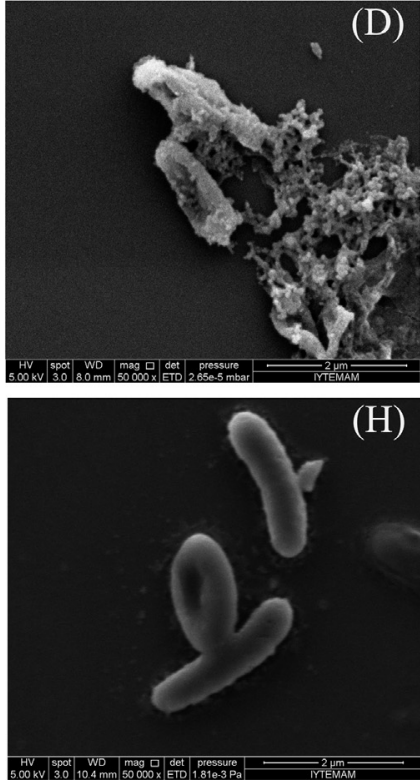

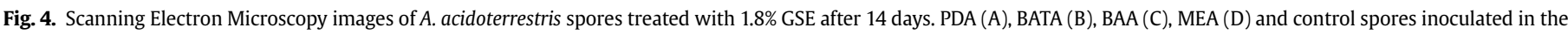
apple juice without GSE after 14 days of treatment PDA (E), BATA (F), BAA (G), MEA (H).

of GSE indicate the formation of perforations in the cell wall (Fig. 3A and $\mathrm{B}$ ) that might be the possible cellular target for GSE. In the apple juice with $0.9 \%$ GSE, the leakage of cellular constituents is observed (Fig. 3C). Besides the changes on the cell structure, GSE also inhibited the development and growth of endospores when treated cells were compared with the control cells (Fig. 3D). While control cells in the apple juice without GSE contain both vegetative cells and spores, only the injured cells are present after GSE treatments. In the related literature (Guendez, Kallithraka, Makris, \& Kefalas, 2005), catechin (49.8\%) and epicatechin (26.0\%) were found as the major constituent of the grape seeds followed by epicatechin gallate (9.3\%), procyanidin B1 (5.8\%) and B2 (5.1\%), epigallocatechin gallate $(1.9 \%)$ and gallic acid (1.3\%). Indeed, phenolic compounds attack bacterial cell wall and cell membranes. These compounds can interact with the membrane proteins by means of hydrogen bonding through their hydroxyl groups which can cause changes in membrane permeability and result in cell destruction. Phenolic components can also penetrate into bacterial cells and coagulate cell content (Tian, Li, Ji, Zhang, \& Luo, 2009). In addition, they interfere with membrane function such as electron transport, nutrient uptake, protein and nucleic acid synthesis and enzyme activity (Paul, Dubey, Maheswari, \& Kang, 2011). In the related literature, the antimicrobial mechanism of some individual components of GSE on the cell structure has been studied. Gallic acid can effectively permeabilize the outer membrane of Salmonella spp. provoking its disintegration based on chelation of divalent cations (Nohynek et al., 2006). The antibacterial mechanism of catechins have been mainly attributed to cytoplasmic membrane damage, although other mechanisms could be involved (Cushnie \& Lamb, 2011). In addition, the mechanism of the antimicrobial activity of epigallocatechin gallate has been attributed to its effect on cell wall components (Zhao, Hu, Hara, \& Shimamura, 2002).

The antimicrobial activity of GSE on spores was different from bacterial cells (Fig. 4). After $336 \mathrm{~h}$ of incubation, the use of $1.8 \%$ concentration of GSE did not affect the integrity of spores produced on PDA (Fig. 4A), BATA (Fig. 4B) and BAA (Fig. 4C). The damage to spores produced on MEA after GSE treatment is clearly observed (Fig. 4D). In fact, the growth control of spores from PDA (Fig. 4E), BATA (Fig. 4F), BAA (Fig. 4G) and MEA (Fig. 4H) in apple juice without GSE contain both vegetative cells and spores. Among treated spores, the development of spores into vegetative cells is not visualized. Indeed, neutral phenolic compounds in red grape prevent the spoilage by Alicyclobacillus spp. Similar to our findings, the addition of catechin gallate into the apple juice was found to inhibit the endospore germination of Alicyclobacillus (Splittstoesser, Churey, \& Lee, 1994).

\section{Conclusions}

The results of the present study demonstrated the potential use of GSE to inhibit the growth of $A$. acidoterrestris cells and spore germination/outgrowth in the apple juice. The antimicrobial activity of GSE may be partly due to its high total phenol content. Considering the results obtained using SEM, it can be concluded that the main target of the GSE might be the cell membrane of A. acidoterrestris. However, further research is needed to determine the mechanism of GSE against spores and the reason for the variability among the sensitivity of spores against GSE depending on the composition of sporulation media.

\section{Acknowledgments}

The authors thank to the members of the Center for Materials Research (IZTECH MAM) for SEM imaging.

\section{References $^{1}$}

Alberice, J. V., Funes-Huacca, M. E., Guterres, S. B., \& Carrilho, E. (2012). Inactivation of Alicyclobacillus acidoterrestris in orange juice by saponin extracts combined with heat-treatment. International Journal of Food Microbiology, 159(2), $130-135$.

Al-Zoreky, N. S. (2009). Antimicrobial activity of pomegranate (Punica granatum L.) fruit peels. International Journal of Food Microbiology, 134(3), 244-248.

\footnotetext{
1 *The selected key references explain the importance of the control of A. acidoterrestris in fruit juices, the potential use of natural compounds to prevent spoilage, the possible mode of action of grape seed extracts and the necessity of the modeling inactivation kinetics of natural antimicrobials for food industry.
} 
Bahçeci, S. K., Gökmen, V., \& Acar, J. (2005). Formation of guaiacol from vanillin by Alicyclobacillus acidoterrestris in apple juice: a model study. European Food Research and Technology, 220(2), 196-199.

Berney, M., Weilenmann, H. U., Simonetti, A., \& Egli, T. (2006). Efficacy of solar disinfection of Escherichia coli, Shigella flexneri, Salmonella Typhimurium and Vibrio cholerae. Journal of Applied Microbiology, 101(4), 828-836.

Bevilacqua, A., Campaniello, D., Speranza, B., Sinigaglia, M., \& Corbo, M. R. (2013). Control of Alicyclobacillus acidoterrestris in apple juice by citrus extracts and a mild heat-treatment. Food Control, 31(2), 553-559.

Bevilacqua, A., Sinigaglia, M., \& Corbo, M. R. (2008). Alicyclobacillus acidoterrestris: new methods for inhibiting spore germination. International Journal of Food Microbiology, 125(2), 103-110.

Bi, X., Liu, F., Rao, L., Li, J., Liu, B., Liao, X., et al. (2013). Effects of electric field strength and pulse rise time on physicochemical and sensory properties of apple juice by pulsed electric field. Innovative Food Science and Emerging Technologies, 17(0), 85-92.

Bijak, M., Bobrowski, M., Borowiecka, M., Podsedek, A., Golanski, J., \& Nowak, P. (2011). Anticoagulant effect of polyphenols-rich extracts from black chokeberry and grape seeds. Fitoterapia, 82(6), 811-817.

van Boekel, M. A. J. S. (2002). On the use of the Weibull model to describe thermal inactivation of microbial vegetative cells. International Journal of Food Microbiology, 74(1-2), 139-159.

Chang, S. S., \& Kang, D. H. (2004). Alicyclobacillus spp. in the fruit juice industry: history, characteristics, and current isolation/detection procedures. Critical Reviews in Microbiology, 30(2), 55-74.

Cushnie, T. P. T., \& Lamb, A. J. (2011). Recent advances in understanding the antibacterial properties of flavonoids. International Journal of Antimicrobial Agents, 38(2), 99-107.

Darland, G., \& Brock, T. D. (1971). Bacillus acidocaldarius sp.nov., an acidophilic thermophilic spore-forming bacterium. Journal of General Microbiology, 67(1) 9-15.

Davidson, P. M., Taylor, M. T., Critzer, F. J., \& Taylor, T. M. (2013). Naturally occurring antimicrobials for minimally processed foods. Annual Review of Food Science and Technology, 4(1), 163-190.

*De Oliveira, T. L. C., Soares, R. D. A., \& Piccoli, R. H. (2013). A Weibull model to describe antimicrobial kinetics of oregano and lemongrass essential oils against Salmonella Enteritidis in ground beef during refrigerated storage. Meat Science, 93(3), 645-651.

Delgado Adámez, J., Gamero Samino, E., Valdés Sánchez, E., \& González-Gómez, D (2012). In vitro estimation of the antibacterial activity and antioxidant capacity of aqueous extracts from grape-seeds (Vitis vinifera L.). Food Control, 24(1-2), 136-141.

Geeraerd, A. H., Herremans, C. H., \& Van Impe, J. F. (2000). Structural model requirements to describe microbial inactivation during a mild heat treatment. International Journal of Food Microbiology, 59(3), 185-209.

Geeraerd, A. H., Valdramidis, V. P., \& Van Impe, J. F. (2005). GInaFiT, a freeware tool to assess non-log-linear microbial survivor curves. International Journal of Food Microbiology, 102(1), 95-105.

Gocmen, D., Elston, A., Williams, T., Parish, M., \& Rouseff, R. L. (2005). Identification of medicinal off-flavours generated by Alicyclobacillus species in orange juice using GC-olfactometry and GC-MS. Letters in Applied Microbiology, 40(3), $172-177$.

Guendez, R., Kallithraka, S., Makris, D. P., \& Kefalas, P. (2005). Determination of low molecular weight polyphenolic constituents in grape (Vitis vinifera $\mathrm{sp}$.) seed extracts: correlation with antiradical activity. Food Chemistry, 89(1) $1-9$.

Gutierrez, J., Barry-Ryan, C., \& Bourke, P. (2009). Antimicrobial activity of plant essential oils using food model media: efficacy, synergistic potential and interactions with food components. Food Microbiology, 26(2), 142-150.

Hereu, A., Dalgaard, P., Garriga, M., Aymerich, T., \& Bover-Cid, S. (2012). Modeling the high pressure inactivation kinetics of Listeria monocytogenes on RTE cooked meat products. Innovative Food Science and Emerging Technologies, 16, 305-315.

Izquier, A., \& Gómez-López, V. M. (2011). Modeling the pulsed light inactivation of microorganisms naturally occurring on vegetable substrates. Food Microbiology, 28(6), 1170-1174.

Jayaprakasha, G. K., Selvi, T., \& Sakariah, K. K. (2003). Antibacterial and antioxidant activities of grape (Vitis vinifera) seed extracts. Food Research International, $36(2), 117-122$

Kao, T.-T., Tu, H.-C., Chang, W.-N., Chen, B.-H., Shi, Y.-Y., Chang, T.-C., et al. (2010). Grape seed extract inhibits the growth and pathogenicity of Staphylococcus aureus by interfering with dihydrofolate reductase activity and folate-mediated one-carbon metabolism. International Journal of Food Microbiology, 141(1-2), $17-27$.

Kim, S., Ruengwilysup, C., \& Fung, D. Y. (2004). Antibacterial effect of water-soluble tea extracts on foodborne pathogens in laboratory medium and in a food model. Journal of Food Protection, 67(11), 2608-2612.
Lau, D. W., \& King, A. J. (2003). Pre- and post-mortem use of grape seed extract in dark poultry meat to inhibit development of thiobarbituric acid reactive substances. Journal of Agricultural and Food Chemistry, 51(6), 1602-1607.

Levy, C., Aubert, X., Lacour, B., \& Carlin, F. (2012). Relevant factors affecting microbial surface decontamination by pulsed light. International Journal of Food Microbiology, 152(3), 168-174.

Mafart, P., Couvert, O., Gaillard, S., \& Leguerinel, I. (2002). On calculating sterility in thermal preservation methods: application of the Weibull frequency distribution model. International Journal of Food Microbiology, 72(1-2), 107-113.

Mahmoud, Y. I. (2013). Grape seed extract neutralizes the effects of Cerastes cerastes cerastes post-synaptic neurotoxin in mouse diaphragm. Micron, 44(0), 298-302.

Manach, C., Scalbert, A., Morand, C., Remesy, C., \& Jimenez, L. (2004). Polyphenols: food sources and bioavailability. The American Journal of Clinical Nutrition, 79(5), 727-747.

Murray, M. B., Gurtler, J. B., Ryu, J. H., Harrison, M. A., \& Beuchat, L. R. (2007). Evaluation of direct plating methods to enumerate Alicyclobacillus in beverages. International Journal of Food Microbiology, 115(1), 59-69.

Negi, P. S. (2012). Plant extracts for the control of bacterial growth: efficacy, stability and safety issues for food application. International Journal of Food Microbiology, 156(1), 7-17.

Nohynek, L. J., Alakomi, H. L., Kahkonen, M. P., Heinonen, M., Helander, I. M., Oksman-Caldentey, K. M., et al. (2006). Berry phenolics: antimicrobial properties and mechanisms of action against severe human pathogens. Nutrition and Cancer, 54(1), 18-32.

Paul, S., Dubey, R. C., Maheswari, D. K., \& Kang, S. C. (2011). Trachyspermum ammi (L.) fruit essential oil influencing on membrane permeability and surface characteristics in inhibiting food-borne pathogens. Food Control, 22(5), 725-731.

*Perumalla, A. V. S., \& Hettiarachchy, N. S. (2011). Green tea and grape seed extractsPotential applications in food safety and quality. Food Research International, 44(4), 827-839.

Pettipher, G. L., Osmundson, M. E., \& Murphy, J. M. (1997). Methods for the detection and enumeration of Alicyclobacillus acidoterrestris and investigation of growth and production of taint in fruit juice and fruit juice-containing drinks. Letters in Applied Microbiology, 24(3), 185-189.

Rhodes, P. L., Mitchell, J. W., Wilson, M. W., \& Melton, L. D. (2006). Antilisterial activity of grape juice and grape extracts derived from Vitis vinifera variety Ribier. International Journal of Food Microbiology, 107(3), 281-286.

Rockenbach, I. I., Gonzaga, L. V., Rizelio, V. M., Gonçalves, A. E.d. S. S., Genovese, M. I., \& Fett, R. (2011). Phenolic compounds and antioxidant activity of seed and skin extracts of red grape (Vitis vinifera and Vitis labrusca) pomace from Brazilian winemaking. Food Research International, 44(4), 897-901.

Shi, J., Yu, J., Pohorly, J. E., \& Kakuda, Y. (2003). Polyphenolics in grape seedsbiochemistry and functionality. Journal of Medicinal Food, 6(4), 291-299.

*Silva, F. V. M., \& Gibbs, P. (2001). Alicyclobacillus acidoterrestris spores in fruit products and design of pasteurization processes. Trends in Food Science and Technology, 12(2), 68-74.

Silván, J. M., Mingo, E., Hidalgo, M., de Pascual-Teresa, S., Carrascosa, A. V., \& Martinez-Rodriguez, A. J. (2013). Antibacterial activity of a grape seed extract and its fractions against Campylobacter spp. Food Control, 29(1), 25-31.

Sivarooban, T., Hettiarachchy, N. S., \& Johnson, M. G. (2008). Physical and antimicrobial properties of grape seed extract, nisin, and EDTA incorporated soy protein edible films. Food Research International, 41(8), 781-785.

Splittstoesser, D. F., Churey, J. J., \& Lee, C. Y. (1994). Growth characteristics of aciduric sporeforming bacilli isolated from fruit juices. Journal of Food Protection, 57(12), 1080-1083.

Takahashi, T., Kokubo, R., \& Sakaino, M. (2004). Antimicrobial activities of eucalyptus leaf extracts and flavonoids from Eucalyptus maculata. Letters in Applied Microbiology, 39(1), 60-64.

Tian, F., Li, B., Ji, B., Zhang, G., \& Luo, Y. (2009). Identification and structure-activity relationship of gallotannins separated from Galla chinensis. LWT-Food Science and Technology, 42(7), 1289-1295.

Torres, J. L., Varela, B., Garcia, M. T., Carilla, J., Matito, C., Centelles, J. J., \& Bobet, R (2002). Valorization of grape (Vitis vinifera) byproducts. Antioxidant and biological properties of polyphenolic fractions differing in procyanidin composition and flavonol content. Journal of Agricultural Food Chemistry, 50(26), 7548-7555.

*Walker, M., \& Phillips, C. A. (2008). Alicyclobacillus acidoterrestris: an increasing threat to the fruit juice industry? International Journal of Food Science and Technology, 43(2), 250-260.

Yang, J. Lee, D., Afaisen, S., \& Gadi, R. (2013). Inactivation by lemon juice of Escherichia coli 0157:H7, Salmonella Enteritidis, and Listeria monocytogenes in beef marinating for the ethnic food kelaguen. International Journal of Food Microbiology, 160(3), 353-359.

Zhao, W. H., Hu, Z. Q., Hara, Y., \& Shimamura, T. (2002). Inhibition of penicillinase by epigallocatechin gallate resulting in restoration of antibacterial activity of penicillin against penicillinase-producing Staphylococcus aureus. Antimicrobial Agents and Chemotherapy, 46(7), 2266-2268. 